\title{
Optic chiasm enhancement associated with giant aneurysm and yttrium treated pituitary adenoma
}

\author{
C M Gabriel, J C Stevens, F Bremner, S Brew, G T Plant
}

J Neurol Neurosurg Psychiatry 2004;75:1343-1345. doi: 10.1136/jnnp.2003.028662

A patient with a history of pituitary tumour treated with yttrium 29 years before presented with an asymmetrical chiasmal neuropathy. Magnetic resonance imaging showed a partially thrombosed giant aneurysm of the right internal carotid artery, with enhancement of the chiasm and right optic tract adjacent to the aneurysm. It was thought that, in addition to the effects of compression, a peri-aneurysmal inflammatory reaction had developed, causing breakdown of the blood-brain barrier and consequent inflammatory changes in the optic chiasm. High dose steroid treatment led to significant improvement in vision within two weeks. Steroids may have a role in the acute preservation of vision in similar cases, as well as in cases of deterioration following coiling or embolisation of aneurysms where thrombosis within the aneurysm has been induced.

\section{CASE REPORT}

A 60 year old woman was admitted urgently with a four month history of gradual blurring of vision affecting the left eye. There was no pain and there were no other neurological problems.

In 1974, the patient had been treated for a growth hormone secreting pituitary adenoma with yttrium implants and bromocriptine and had maintained low growth hormone levels since then. There was no visual compromise from the original tumour but we were not able to retrieve any neuroophthalmic assessment from that time. She was taking hydrocortisone as steroid replacement therapy and a diphosphonate for osteoporosis. She was also treated for hypertension and diabetes. In 1967 she had a mastectomy for breast cancer.

On examination she had prognathism and prominent supraorbital ridges, characteristic of acromegaly. Corrected visual acuity was $6 / 6$ on the right, with normal colour vision (Ishihara plates). On the left, acuity was $2 / 60$ and she was only able to read the first (control) Ishihara plate when viewed in the nasal hemifield. Confrontational field testing with a light source showed a temporal hemianopia on the left, and Goldman perimetry showed a generally depressed field with temporal loss respecting the vertical meridian on the right. There was a left relative afferent pupillary defect. The optic discs appeared cupped, but red-free photography did not show corresponding loss of the retinal nerve fibre layer. Her eye movements were normal, as was the rest of the neurological examination, other than distal lower limb sensory loss. General examination was normal but for the previous mastectomy scar.

Growth hormone and other pituitary hormones were normal and prolactin was not raised.
MRI of head and orbits (fig 1) showed chiasmal displacement by a heterogeneous mass lesion, confirmed as a giant aneurysm of the right internal carotid artery by angiography. The mixed signal within the aneurysm represented partial thrombosis and slow or turbulent flow. The chiasm appeared thickened and both the chiasm and the right optic tract enhanced with gadolinium.

As the appearance was compatible with breakdown of the blood-brain barrier in the anterior visual pathway, we supposed that in addition to the effects of compression, the aneurysm may have generated an inflammatory reaction in the adjacent chiasm. The lack of gross evidence for optic atrophy was also compatible with there being a potentially reversible cause of visual impairment. The patient was treated with high dose intravenous methylprednisolone ( $\mathrm{lg} /$ day for three days), then oral prednisolone tapering from $40 \mathrm{mg} /$ day to zero over two weeks. After two weeks there was improvement in vision, with acuity on the left improving to $6 / 18$ and substantial improvement in both visual fields (fig 2). There was no deterioration in either acuity or visual fields when steroids were discontinued.

Because of the risk of further damage to the visual pathways we proceeded to definitive treatment of the aneurysm. Following a successful carotid test occlusion, the patient proceeded to trapping of the right internal carotid artery aneurysm with proximal and distal balloons. She developed a right Horner's syndrome and delayed mild left hemiparesis after becoming hypotensive several days postprocedure. Her left eye acuity improved further to 6/9. She was not given further steroids and her vision has remained stable eight months later.

\section{DISCUSSION}

The high signal and enhancement of the chiasm and optic tract and the response to steroids in our patient make an inflammatory chiasmal neuropathy the most likely explanation for her visual symptoms. There have been no other reports of reversible inflammatory lesions of the anterior visual pathway linked to internal carotid aneurysms other than in association with muslin wrapping. ${ }^{1}$

Various mechanisms may be postulated to explain the chiasmal inflammation. These include a direct effect of chiasmal displacement (mass effect), ischaemia from compression of the blood supply to the chiasm, radiation damage, and an inflammatory reaction around the thrombosed aneurysm.

Optic tract oedema manifesting as high signal on magnetic resonance imaging has been reported in association with intracranial tumours, ${ }^{2-5}$ but compression alone seems an unlikely cause of this, and additional mechanisms have been postulated such as tumour related cytokines ${ }^{3}$ and physical obstruction to drainage of Virchow-Robin spaces. ${ }^{5}$ Certainly, the oedema does not appear to be related to compression per se as it is not seen with the commonest cause of chiasmal compression, pituitary adenoma (personal observation). 

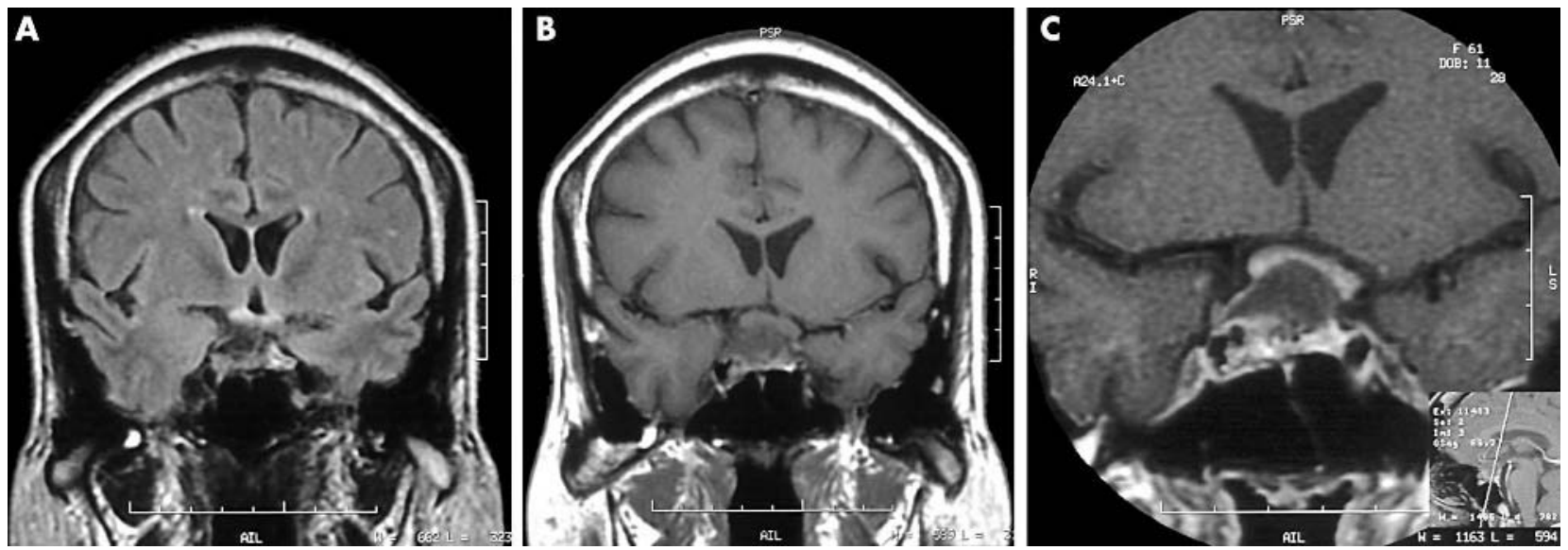

Figure 1 MRI of the brain. A heterogeneous signal intensity sella and suprasellar lesion is shown. The optic chiasm is displaced superiorly and draped over the suprasellar component. The chiasm and proximal right optic tract are of high signal on FLAIR ( $A$ ) and enhance with gadolinium on Tl (B and C).

Thrombosis of an aneurysm, either spontaneous ${ }^{67}$ or following treatment, ${ }^{89}$ may cause neurological deterioration probably because of an increase in aneurysm size, ${ }^{10}$ and this was a possible cause of deterioration in our patient.

The time elapsed since maximum irradiation from yttrium in this case, and the response to steroids, make a radiation induced optic neuropathy unlikely, although it is probable that the aneurysm itself was a secondary effect of radiation. Damage to the carotid arteries by yttrium implants was noted half a century ago ${ }^{11}$ and aneurysms of the cavernous internal carotid artery are now well recognised, though rare. ${ }^{12}{ }^{13}$

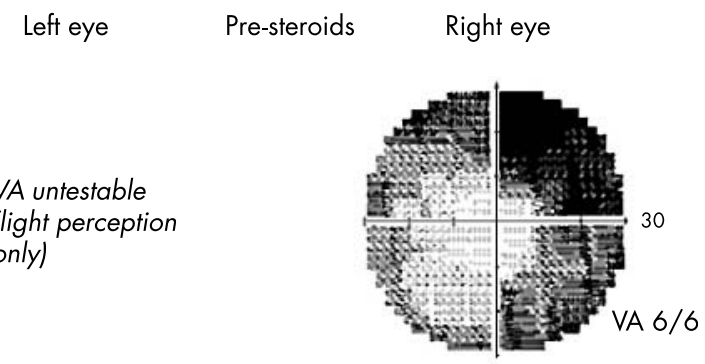

Day 2 of oral steroids
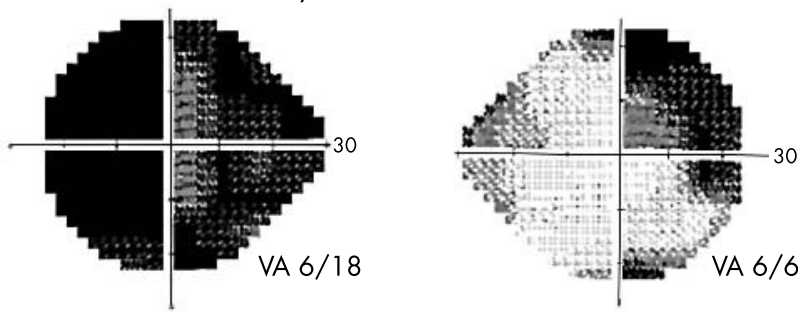

2 days after completing 14 days of oral steroids
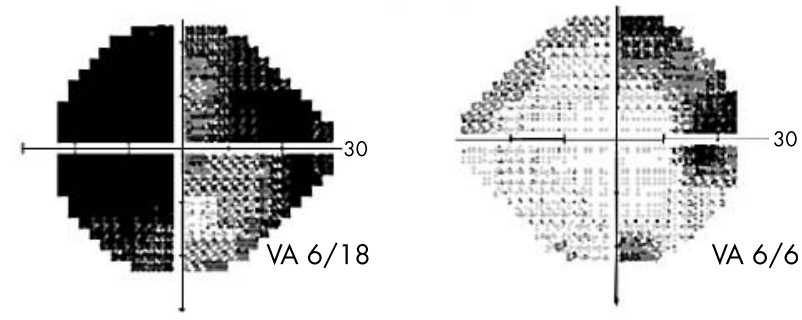

Figure 2 Visual fields before and after steroid treatment.
Intra-aneurysmal thrombosis may have induced perianeurysmal inflammation. Vasoactive factors such as vascular endothelial growth factor (VEGF) are released during platelet aggregation $^{14}$ and have an active role in endothelial permeability; corticosteroids have been shown to reduce the release of VEGF.'

Whether the visual deterioration and enhancing optic chiasm and tract in our case reflected compression or perianeurysmal inflammation, there was a clear response to steroids. Although susceptibility to such pathology in our patient may have been modified by long standing radiation effects on the chiasm, anti-inflammatory treatment could play a role in the acute preservation of vision in similar circumstances. This might also apply to acute deterioration occurring during the monitoring of known giant aneurysms, and extend to deterioration following coiling or embolisation of aneurysms, where thrombosis within the aneurysm has been induced

\section{Authors' affiliations}

C M Gabriel, J C Stevens, G T Plant, Department of Neurology, National Hospital for Neurology and Neurosurgery, Queen Square, London WCl, UK

F Bremner, Department of Ophthalmology, National Hospital for Neurology and Neurosurgery

S Brew, Department of Neuroradiology, National Hospital for Neurology and Neurosurgery

Competing interests: none declared

Correspondence to: $\operatorname{Dr}$ C M Gabriel, Department of Neurology, St Mary's Hospital, Praed St, London W2 1NY; carolyn.gabriel@ St-Marys.nhs.uk

Received 23 September 2003

Revised 11 December 2003

Accepted 18 December 2003

\section{REFERENCES}

1 Bhatti MT, Holder CA, Newman NJ, et al. MR Characteristics of muslininduced optic neuropathy: report of two cases and review of the literature. Am J Neuroradiol 2000;21:346-52.

2 Youl BD, Plant GTP, Stevens JM, et al. Three cases of craniopharyngioma showing optic tract hypersignal on MRI. Neurology 1990;40:1416-19.

3 Sklar EM, Schaz NJ, Glaser JS, et al. Optic tract edema in a meningioma of the tuberculum sellae. Am J Neuroradiol 2000;21:1661-3.

4 Saeki N, Murai $H$, Kubota $M$, et al. Oedema along the optic tract due to pituitary metastasis. Br J Neurosurg 2001;15:523-6.

5 Saeki N, Uchino Y, Murai H, et al. MR imaging study of edema-like change along the optic tract in patients with pituitary region tumours. Am J Neuroradiol 2003;24:336-42. 
6 Miller NR, Savino PJ, Schneider T. Rapid growth of an intracranial aneurysm causing apparent retrobulbar optic neuritis. J Neuroopthalmol 1995; 15:212-18.

7 Aoki N. Partially thrombosed aneurysm presenting as the sudden onset of bitemporal hemianopia. Neurosurgery 1988;22:564-6.

8 Litofsky NS, Vinuela F, Giannotta SL. Progressive visual loss after electrothrombosis treatment of a giant intracranial aneurysm: Case report. Neurosurgery 1995;34:548-51.

9 Blanc R, Weill A, Piotin M, et al. Delayed stroke secondary to increasing mass effect after endovascular treatment of a giant aneurysm by parent vessel occlusion. Am J Neuroradiol $2001 ; 22: 841-3$.
10 Heros RC. Partially thrombosed aneurysm presenting as the sudden onset of bitemporal hemianopsia. Neurosurgery 1988;22:566.

11 Rasmussen T, Harper PV, Kennedy T. The use of a beta ray point source for destruction of the hypophysis. Surg Forum 1953;4:681.

12 Thun $\mathbf{F}$, Lanfermann $\mathrm{H}$. Intracranial giant aneurysms induced by irradiation. Radiologe 1991;31:244-6.

13 McConachie NS, Jacobson I. Bilateral aneurysms of the cavernous internal carotid arteries following yttium-90 implantation. Neuroradiology 1994;36:611-13.

14 Maloney JP, Silliman CC, Ambruso DR, et al. In vitro release of vascular endothelial growth factor during platelet aggregation. Am J Physiol 1998;275:H1054-61.

\section{HISTORICAL NOTE}

\section{The Argyll Robertson pupil}

n 1869 Douglas Moray Cooper Lamb Argyll Robertson described his famous pupillary sign in two papers:

"I could not observe any contraction of either pupil under the influence of light, but, on accommodating the eyes for a near object, both pupils contracted. ${ }^{\prime \prime} 2$

Argyll Robertson was one of the first surgeons to specialise in ophthalmology. Pupillary miosis, inequality, and irregularity, without reaction to light, had been known in cases of tabes dorsalis and dementia paralytica (GPI) since the end of the 18th century.

Ernst Julius Remak had shown the pupillary signs of tabes to Argyll Robertson, ${ }^{3}$ whose later famous reports of 1869 acknowledged Remak's observation of the miotic pupil, its defective reaction to light, and preserved contraction on accommodation. Romberg (1839) also gave an earlier description. $^{3}$

The Argyll Robertson pupil soon became a "pathognomonic sign" in tabes dorsalis, dementia paralytica, and meningovascular syphilis. However, the role of syphilis in causing these disorders was hotly debated. Jean Alfred Fournier and Sir Jonathan Hutchinson (1828-1913) favoured a syphilitic aetiology, but not until the 20th century was it generally accepted as the cause. Crucial to this were the discoveries by Schaudinn and Hoffmann of the treponema pallidum in 1905 and the serologic test in 1906 of August Paul von Wassermann(1866-1925).

The abnormal pupil is probably caused by damage to cells in the pretectal region of the midbrain. As a result, signals carried from the retina are not relayed via the pretectal nucleus on the affected side to the Edinger-Westphal nuclei. This causes a loss of both the direct and consensual pupillary light reflexes. Since the accommodation reflex pathway is separate from the light reflex it is unaffected. Pupillary inequality, irregularity, and iris atrophy without reaction to light are the hallmarks, clinically distinguishable from the Holmes-Adie myotonic pupil. Walshe stated ${ }^{4}$ that "these components though varying from case to case are never found together apart from neurosyphilis". Others claim it occurs rarely in Wernicke's encephalopathy and diabetes.

Argyll Robertson was born in 1837 in Edinburgh, ${ }^{5}$ where his father, John, was a general surgeon, who concentrated on eye surgery. He graduated at St Andrews, in 1857, returned as a house surgeon to the Edinburgh Royal Infirmary, then studied in Berlin under the leading ophthalmologist Albrecht von Graefe (1828-1870). He became lecturer in diseases of the eye at the Edinburgh Medical School in 1862. In 1863, he published an important article $^{6}$ on the Calabar bean
(Physostigmin venosum), the seed of a leguminous plant found in Calabar, Nigeria. Argyll Robertson instilled an extract into his own eye noting that physostigmine constricts the pupil. He predicted it would become "most valuable in the ophthalmic pharmacopoeia".

In 1867 he was appointed assistant ophthalmic surgeon, and in 1870 full ophthalmic surgeon to the Royal Infirmary, where he stayed until retirement in 1897.

Physostigmine from the calabar beam was to be important in the treatment of glaucoma. Argyll Robertson was also the first to describe a trepanning method of operation for certain cases of glaucoma. He became chairman of the ophthalmologic society of England, 1886, held office in the Royal College of Surgeons of Edinburgh, and was honorary eye physician to Queen Victoria and King Edward VII. In 1904, for health reasons, he moved to the Jersey. While on holiday in India in 1908 he became ill in Gondal near Bombay, and died.

His biographer noted

"His handsome features and his tall, athletic frame made him the cynosure of all female eyes in his youth and in his later years, clad in a grey frock-coat and top hat, his dignified manner combined with his genial old-world courtesy made him conspicuous in any assembly and a magnificent ambassador of Scotland." 7

A keen golfer, he won the gold medal of the Royal and Ancient Club, St Andrews, five times.

304 Beverley Road, Anlaby, Hull HU10 7BG; imspearce@freenet.co.uk doi: 10.1136/jnnp.2003.014225

\section{References}

1 Argyll Robertson, DMCL. On an interesting series of eye symptoms in a case of spinal disease, with remarks on the action of belladonna on the iris. Edin Med J 1869; 14:696-708.

2 Argyll Robertson, DMCL. Four cases of spinal miosis: with remarks on the action of light on the pupil. Edin Med J 1869;15:487-93.

3 Leake CD. Douglas Argyll Robertson. In: Haymaker W, Schiller F, eds. The Founders of Neurology, 2nd edn. Springfield: Charles C Thomas, 1970:505.

4 Walshe FMR. Diseases of the nervous system, 10th edn. Edinburgh: Livingstone, 1963:185.

5 Obituary. Edin Med J 1909;3rd series:159-162.

6 Argyll Robertson, DMCL. The Calabar bean as a new agent in ophthalmic medicine. Edin Med J 8:1862-1863.

7 Burnett JDC. Argyll Robertson? a breadth of vision. J Med Biography 1993;1:186-188. 